\title{
PERBEDAAN NYERI PADA PASIEN PASCA BEDAH FRAKTUR EKSTREMITAS SEBELUM DAN SESUDAH DILAKUKAN TEKNIK RELAKSASI NAPAS DALAM
}

\author{
Prita Devy Igiany \\ Program Studi Perekam \& Informasi Kesehatan, FKM, Universitas Veteran Bangun Nusantara \\ Email: pritadevyigiany90@gmail.com
}

\begin{abstract}
Pain is a problem which always experienced by patients who have post-surgical extremity fracture. Pharmacology therapies are not always the answer to reduce the pain, so that we need nonpharmacology therapies too as the result. Deep breathing relaxation technique is one type of nonpharmacology therapies to reduce post-surgical pain. This research aim to find the difference of pain degree between post-surgical pain before and after did a deep breathing relaxation technique. The research used quasi experimental method and purposive sampling technique, which divide 30 people to two group, control group and experiment group. Post-surgical pain after received deep breathing relaxation technique analyzed by T-Independent and T-Dependent test. The result of this research showed the significant difference between before and after they received deep breathing relaxation technique $(\mathrm{p}<0,05)$.
\end{abstract}

Keywords : deep breathing, post-surgical pain, extremity fracture

\begin{abstract}
ABSTRAK
Nyeri merupakan masalah yang selalu dialami oleh pasien pasca bedah fraktur ekstremitas. Pemberian terapi farmakologis terkadang tidak selalu dapat menurunkan rasa nyeri sehingga perlu di dukung dengan terapi nonfarmakologis. Teknik relaksasi napas dalam adalah salah satu jenis terapi nonfarmakologis untuk mengurangi nyeri pasca bedah. Penelitian ini bertujuan untuk mengetahui perbedaan derajat nyeri pasca bedah fraktur ekstremitas sebelum dan sesudah dilakukan teknik relaksasi napas dalam. Metode penelitian ini adalah kuasi eksperimen dengan menggunakan 30 sampel yang dibagi menjadi 15 sampel kelompok kontrol dan 15 sampel kelompok eksperimen. Analisa nyeri pasca bedah dianalisis dengan uji $T$ Independent dan uji $T$ Dependent. Hasil penelitian menunjukkan adanya perbedaan rata-rata intensitas nyeri pasca bedah yang signifikan sebelum dan sesudah dilakukan teknik relaksasi napas dalam pada kelompok eksperimen $(\mathrm{p}<0.05)$.

Kata kunci : napas dalam, nyeri pasca bedah, fraktur ekstremitas
\end{abstract}




\section{PENDAHULUAN}

Pembedahan yang dilakukan pada pasien fraktur ekstremitas dapat mengakibatkan nyeri berat selama beberapa hari pasca bedah. Nyeri yang timbul terasa tajam dan menusuk akibat adanya edema, hematoma dan spasme otot (Smeltzer \& Bare, 2002a). Nyeri pasca bedah yang tidak segera diatasi akan menimbulkan rasa cemas, ketakutan, depresi dan bahkan paranoid. Respon hemodinamik yang muncul terhadap nyeri adalah takikardi dan hipertensi, yang akan meningkatkan konsumsi oksigen ke miokardium. Selain itu nyeri pasca bedah juga dapat meningkatkan pernapasan dan membatasi mobilisasi pasien sehingga dapat menimbulkan penyakit lain akibat imobilisasi (Hambly \& Sainsbury, 2007).

Nyeri bersifat subjektif, tidak ada dua individu yang mengalami nyeri yang sama dan tidak ada dua kejadian nyeri yang sama menghasilkan respon atau perasaan yang identik pada seorang individu. Nyeri pasca bedah merupakan sumber penyebab frustasi baik bagi klien maupun tenaga kesehatan. Asosiasi Internasional untuk penelitian nyeri (International Association for the Study of Pain, $I A S P$ ) mendefinisikan nyeri sebagai suatu sensori subjektif dan pengalaman emosional yang tidak menyenangkan berkaitan dengan kerusakan jaringan yang aktual atau potensial dalam kejadian terjadinya kerusakan. Nyeri pasca bedah dapat menjadi faktor utama yang menghambat kemampuan dan keinginan individu untuk pulih dari penyakit (Potter \& Perry, 2006).

Penanganan nyeri melalui intervensi farmakologis dapat dilakukan dengan memberikan obat-obatan analgesik kepada pasien secara parenteral maupun oral (Smeltzer \& Bare, 2002b). Namun pemberian analgesik jangka panjang akan menimbulkan efek samping seperti mual, muntah, konstipasi, depresi pernapasan, adiksi serta pruritus. Karena itu terapi nonfarmakologik biasanya dikombinasikan dengan terapi farmakologis untuk meningkatkan efek analgesik (Potter \& Perry, 2006; Price \& Wilson, 2006).

Teknik relaksasi napas dalam merupakan salah satu metode manajemen nyeri nonfarmakologis dalam teknik penanggulangan nyeri pasca bedah (Potter \& Perry, 2006). Teknik relaksasi napas dalam dipercaya dapat menurunkan intensitas nyeri dengan merelaksasikan otot-otot skelet yang mengalami spasme yang disebabkan oleh peningkatan prostaglandin sehingga terjadi vasodilatasi pembuluh darah dan akan meningkatkan aliran darah ke daerah yang mengalami spasme dan iskemik. Relaksasi napas dalam melibatkan sistem otot dan respirasi dan tidak membutuhkan alat lain sehingga mudah dilakukan kapan saja atau sewaktu-waktu nyeri muncul (Jayanthi, 2010).

Sebuah studi baru menemukan bahwa teknik relaksasi napas dalam dapat membantu pasien mengatasi rasa sakit dan kecemasan setelah operasi. Ohio (2006) melakukan penelitian tentang nyeri pada pasien pasca bedah yang hanya mendapat analgesik tanpa napas dalam dan pasien yang mendapat kedua terapi. Penelitian ini menggunakan sampel sebanyak dua puluh orang sebagai kelompok kontrol dan dua puluh orang sebagai kelompok eksperimen. Kelompok eksperimen mendapat terapi analgesik dan mendapat perlakuan teknik napas dalam, sedangkan kelompok kontrol hanya diberikan analgesik dan tidak melakukan napas dalam. Setelah prosedur napas dalam, peneliti mengukur skala nyeri pasien, dan hasil penelitian menunjukkan bahwa terjadi penurunan skala nyeri yang bermakna setelah mendapat perlakuan teknik napas dalam (Shirley, 2009).

Penelitian lain mengenai teknik relaksasi juga pernah dilakukan oleh Artini (2009) dengan jumlah sampel 36 orang. Ia menyatakan bahwa ada perbedaan yang bermakna $(p=0,000)$ antara tingkat nyeri pasca operasi di RSUP Dr. Soeradji Tirtonegoro Klaten sebelum dan sesudah dilakukan napas dalam. Sedangkan Priyani (2009) melakukan penelitian pada remaja putri mengenai nyeri disminore. Hasil penelitian yang di lakukan pada 30 sampel juga menunjukkan bahwa ada pengaruh yang bermakna $(\mathrm{p}=0,000)$ pemberian teknik relaksasi nafas dalam terhadap penurunan nyeri disminore pada remaja putri.

Dari hasil wawancara peneliti kepada pasien pasca bedah fraktur ekstremitas yang berada di ruangan Cendrawasih II, 6 dari 7 pasien merasakan nyeri pasca bedah yang menurut pasien menganggu aktivitas. Sedangkan menurut perawat ruangan praktek teknik napas 
dalam di RSUD Arifin Achmad masih jarang dilakukan khususnya pada pasien pasca bedah fraktur. Berdasarkan hal tersebut maka peneliti tertarik untuk melakukan penelitian tentang Perbedaan Nyeri Pada Pasien Pasca Bedah Fraktur Sebelum dan Sesudah Dilakukan Teknik Relaksasi Napas Dalam.

\section{METODE}

Penelitian ini merupakan penelitian kuantitatif yang akan menggunakan rancangan penelitian Quasi Eksperimental, dengan pendekatan pretest-posttest design with control group. Populasi penelitian adalah pasien dengan diagnosa medis pasca bedah fraktur ekstremitas dengan jumlah sampel 30 orang yang diambil dengan teknik purposive sampling. Analisa bivariat yang digunakan dalam penelitian ini adalah uji t Independent dan uji t Dependent untuk membandingkan rata-rata intensitas nyeri antara kelompok kontrol dan kelompok eksperimen.

\section{HASIL}

Tabel 1

Distribusi Kategori Nyeri Pasca Bedah Sebelum Pemberian Teknik Napas Dalam pada Kelompok Kontrol dan Kelompok Eksperimen

\begin{tabular}{lcccccc}
\hline \multirow{2}{*}{$\begin{array}{c}\text { Kategori } \\
\text { Nyeri }\end{array}$} & \multicolumn{2}{c}{$\begin{array}{c}\text { Kelompok } \\
\text { Kontrol }\end{array}$} & \multicolumn{2}{c}{$\begin{array}{c}\text { Kelompok } \\
\text { Eksperimen }\end{array}$} & \multicolumn{2}{c}{$\begin{array}{c}\text { Total } \\
(\mathrm{N}=30)\end{array}$} \\
\cline { 2 - 7 } & $\mathrm{n}$ & $\%$ & $\mathrm{~N}$ & $\%$ & $\mathrm{~N}$ & $\%$ \\
\hline $\begin{array}{l}\text { Tidak } \\
\text { Nyeri }\end{array}$ & 0 & 0 & 0 & 0 & 0 & 0 \\
$\begin{array}{l}\text { Nyeri } \\
\text { Ringan }\end{array}$ & 0 & 0 & 0 & 0 & 0 & 0 \\
$\begin{array}{l}\text { Nyeri } \\
\text { Sedang }\end{array}$ & 9 & 30.00 & 9 & 30.00 & 18 & 60.00 \\
$\begin{array}{l}\text { Nyeri } \\
\text { Berat }\end{array}$ & 6 & 20.0 & 6 & 20.0 & 12 & 40.00 \\
$\begin{array}{l}\text { Nyeri } \\
\text { Sangat } \\
\text { Berat }\end{array}$ & 0 & 0 & 0 & 0 & 0 & 0 \\
\hline
\end{tabular}

Tabel di atas menunjukkan bahwa distribusi intensitas nyeri pasca bedah sebelum dilakukan teknik napas dalam (pretest) mempunyai intensitas nyeri sedang $(60.00 \%)$.
Tabel 2

Distribusi Kategori Nyeri Pasca Bedah Sesudah Pemberian Teknik Napas Dalam pada Kelompok Kontrol dan Kelompok Eksperimen

\begin{tabular}{lcccccc}
\hline \multirow{2}{*}{$\begin{array}{c}\text { Kategori } \\
\text { Nyeri }\end{array}$} & \multicolumn{2}{c}{$\begin{array}{c}\text { Kelompok } \\
\text { Kontrol }\end{array}$} & \multicolumn{2}{c}{ Kelompok } \\
Eksperimen & \multicolumn{2}{c}{$\begin{array}{c}\text { Total } \\
(\mathrm{N}=30)\end{array}$} \\
\cline { 2 - 7 } & $\mathrm{n}$ & $\%$ & $\mathrm{~N}$ & $\%$ & $\mathrm{~N}$ & $\%$ \\
\hline $\begin{array}{l}\text { Tidak } \\
\text { Nyeri }\end{array}$ & 0 & 0 & 1 & 3.30 & 1 & 3.30 \\
$\begin{array}{l}\text { Nyeri } \\
\text { Ringan }\end{array}$ & 9 & 30.0 & 11 & 36.70 & 20 & 66.70 \\
$\begin{array}{l}\text { Nyeri } \\
\text { Sedang }\end{array}$ & 6 & 20.0 & 3 & 10.00 & 91 & 30.00 \\
$\begin{array}{l}\text { Nyeri } \\
\text { Berat } \\
\text { Nyeri }\end{array}$ & 0 & 0 & 0 & 0 & 0 & 0 \\
$\begin{array}{l}\text { Sangat } \\
\text { Berat }\end{array}$ & 0 & 0 & 0 & 0 & 0 & 0 \\
\hline
\end{tabular}

Berdasarkan tabel di atas dapat diketahui intensitas nyeri responden mengalami penurunan dengan mayoritas responden mempunyai intensitas nyeri ringan $(66.70 \%)$.

Tabel 3

Perbandingan Rata-Rata Intensitas Nyeri Pasca Bedah Antara Sebelum dan Sesudah Pemberian Napas Dalam

\begin{tabular}{|c|c|c|c|c|c|}
\hline \multirow{3}{*}{ Kelompok } & \multicolumn{4}{|c|}{ Intensitas Nyeri } & \multirow{3}{*}{$p$-value } \\
\hline & \multicolumn{2}{|c|}{ Pre-test } & \multicolumn{2}{|c|}{ Pos-ttest } & \\
\hline & Mean & $\mathrm{SD}$ & Mean & $\mathrm{SD}$ & \\
\hline Kontrol & 6.00 & 1.46 & 3.27 & 1.38 & 0.00 \\
\hline Eksperimen & 6.33 & 1.35 & 2.13 & 1.18 & 0.00 \\
\hline \multicolumn{6}{|c|}{$\begin{array}{l}\text { Hasil dari uji T Dependent menunjukkan bahwa } \\
\text { ada perbedaan yang signifikan rata-rata intensitas } \\
\text { nyeri antara sebelum dan sesudah pemberian } \\
\text { teknik napas dalam }(\mathrm{p}<0.05) \text {. }\end{array}$} \\
\hline \multicolumn{6}{|c|}{$\begin{array}{l}\text { Tabel } 4 \\
\text { Perbandingan Rata-Rata Intensitas Nyeri Pasca } \\
\text { Bedah Antara Kelompok Kontrol dan Kelompok } \\
\text { Eksperimen }\end{array}$} \\
\hline Nyeri & \multicolumn{4}{|c|}{ Mean } & p-value \\
\hline $\begin{array}{l}\text { Pasca } \\
\text { Bedah }\end{array}$ & \multicolumn{2}{|c|}{$\begin{array}{c}\text { Kelompok } \\
\text { Kontrol }\end{array}$} & \multicolumn{2}{|c|}{$\begin{array}{l}\text { Kelompok } \\
\text { Eksperimen }\end{array}$} & \\
\hline $\begin{array}{l}\text { Nyeri Pre- } \\
\text { test }\end{array}$ & 6.0 & & 6.3 & & 0.52 \\
\hline $\begin{array}{l}\text { Nyeri Post- } \\
\text { test }\end{array}$ & 3.2 & & 2.1 & & 0.02 \\
\hline
\end{tabular}

Hasil uji statistik menunjukkan bahwa perbedaan rata-rata intensitas nyeri pasca bedah tidak signifikan sebelum diberikan teknik napas dalam $(\mathrm{p}>0.05)$. 
Grafik 1

Grafik perbandingan rata-rata intensitas nyeri pasca bedah antara kelompok kontrol dan kelompok eksperimen

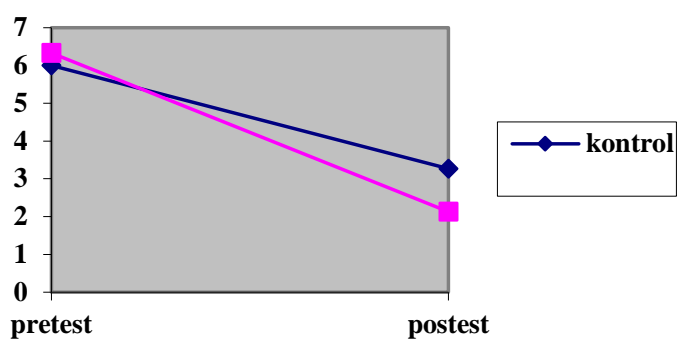

\section{PEMBAHASAN}

Hasil analisa menunjukkan bahwa responden mayoritas menyatakan bahwa ia merasakan nyeri berat $(60 \%)$ sebelum dilakukan teknik relaksasi napas dalam. Setelah dilakukan teknik relaksasi napas dalam (post-test) mayoritas responden merasakan intensitas nyeri ringan $(66.70 \%)$. Nyeri akibat pasca bedah menurut Smeltzer dan Bare (2002) akan timbul dalam 48 jam pertama setelah pembedahan dengan skala sedang-berat. Nyeri pasca bedah dapat timbul karena adanya luka insisi, dan juga karena efek anastesi yang sudah hilang dan pasien sudah sadar sehingga rasa nyeri lebih dirasakan oleh pasien (Sjamsuhidajat \& Jong, 2005). Harsono (2010) menyatakan dalam penelitiannya bahwa walaupun nyeri telah dikelola dengan baik, kira-kira $86 \%$ dari pasien pasca bedah mengalami nyeri sedang ke hebat pasca bedah meskipun analgesik ditingkatkan .

Menurut Smeltzer dan Bare (2002) intensitas nyeri juga dapat dipengaruhi karakteristik lain seperti umur dan jenis kelamin. Hasil penelitian menunjukkan bahwa mayoritas responden adalah dewasa awal (53.30\%) yang berjenis kelamin laki-laki (90\%). Hasil studi yang dilakukan Chou dan Vivian (dalam Putra, 2010) menyatakan laki-laki dan perempuan tidak berbeda secara bermakna dalam berspon terhadap nyeri yang mungkin disebabkan adanya faktor lain yang dapat mempengaruhi nyeri seperti budaya. Dalam penelitian ini suku Melayu adalah suku mayoritas dari responden (46.70\%).
Intensitas nyeri pasca bedah sebelum dilakukan teknik napas dalam pada kelompok kontrol dan kelompok eksperimen tidak ada perbedaan yang signifikan dengan nilai $\mathrm{p}=0.52$ $(p>0.05)$. Hal ini mungkin dikarenakan responden belum mendapatkan intervensi untuk mengurangi rasa nyerinya sehingga nyeri masih dirasakan oleh responden. Sedangkan setelah dilakukan teknik napas dalam pada kelompok eksperimen hasil penelitian menunjukkan ratarata intensitas nyeri menurun dan menunjukkan adanya perbedaan yang signifikan antara sebelum dan sesudah dilakukan teknik relaksasi napas dalam dengan nilai $\mathrm{p}=0.02(\mathrm{p}<0.05)$. Hal tersebut mungkin karena responden pada kelompok kontrol tidak diberikan perlakuan teknik relaksasi napas dalam seperti halnya pada kelompok eksperimen sehingga rata-rata intensitas nyeri kelompok kontrol masih lebih tinggi dari pada kelompok eksperimen.

Teknik relaksasi napas dalam adalah salah satu terapi nonfarmakologis untuk mengurangi rasa nyeri yang dirasakan pasien pasca bedah fraktur ekstremitas. Terapi ini dilakukan untuk membantu mengoptimalkan efek dari terapi farmakologi yang diberikan kepada pasien. Teknik relaksasi napas dalam diberikan kepada pasien selama tiga hari dan dilakukan dua kali sehari sebanyak 20 kali (Smeltzer \& Bare, 2002).

Penurunan intensitas nyeri disebabkan karena teknik relaksasi napas dalam dapat merangsang tubuh untuk mengeluarkan opioid endogen yang akan menghambat impuls nyeri sehingga dapat menurunkan persepsi nyeri pasien. Hal ini sejalan dengan penelitian yang dilakukan Ilmi (2010), mengenai efektifitas terapi napas dalam terhadap perubahan skala nyeri pada pasien post operasi laparatomi yang menggunakan 15 responden sebagai kelompok eksperimen yang melakukan teknik relaksasi napas dalam selama 10 sampai 20 menit menunjukkan bahwa kelompok yang melakukan teknik napas dalam mengalami penurunan derajat nyeri yang signifikan dibandingkan dengan kelompok yang tidak melakukan teknik relaksasi napas dalam dengan nilai $\mathrm{p}=0.000$.

Penelitian lain yang dilakukan oleh Roykulcharoen dan Good (2004) dalam Ilmi (2010) juga menyatakan bahwa responden yang 
melakukan teknik relaksasi merasakan penurunan tingkat nyeri dengan nilai $\mathrm{p}=0.000$. Hasil penelitian menunjukkan bahwa pemberian teknik relaksasi napas dalam dapat menurunkan intensitas nyeri lebih besar dibandingkan responden yang tidak diberikan perlakuan teknik relaksasi napas dalam sehingga dapat dikatakan terdapat perbedaan nyeri pasien fraktur ekstremitas antara sebeum dan sesudah dilakukan teknik relaksasi napas dalam.

\section{SIMPULAN}

Rata-rata intensitas nyeri pasca bedah sebelum dilakukan teknik relaksasi napas dalam pada kelompok kontrol menunjukan ada perbedaan yang tidak signifikan $(p>0.05)$. Sedangkan rata-rata intensitas nyeri pasca bedah sesudah dilakukan teknik relaksasi napas dalam pada kelompok kontrol terdapat perbedaan yang signifikan $(\mathrm{p}<0.05)$. Kelompok eksperimen menunjukkan ada perbedaan yang signifikan antara sebelum dan sesudah diberikan teknik relaksasi napas dalam $(\mathrm{p}<0.05)$.

Dari hasil penelitian dapat disimpulkan bahwa terdapat perbedaan nyeri pasca bedah fraktur ekstremitas antara sebelum dan sesudah dilakukan teknik relaksasi napas dalam.

\section{DAFTAR PUSTAKA}

Artini, N. K. R. (2009). Abstrak Pengaruh Pemberian Teknik Relaksasi Nafas Dalam Terhadap Tingkat Nyeri Pasca Operasi Di RSUP Dr. Soeradji Tirtonegoro Klaten. Diperoleh pada tanggal 19 Agustus 2010 dari

http://skripsistikes.wordpress.com/2009/0 5/03/ikpiii98/.

Ayudianingsih, N.G. (2009). Pengaruh Teknik Relaksasi Nafas Dalam Terhadap Penurunan Tingkat Nyeri Pada Pasien Pasca Operasi Fraktur Femur Di Rumah Sakit Karima Utama Surakarta. Diperoleh pada tanggal 26 September 2010 dari http://etd.eprints.ums.ac.id/6424/
Chang, E., Daly, J., \& Elliott, D. (2010). Patofisiologi Aplikasi pada Praktik Keperawatan. Jakarta: EGC.

Fitria, D. (2010). Efektifitas Kombinasi Aroma Terapi dan Teknik Napas Dalam Terhadap Nyeri Fase Aktif Kala I Persalinan. Skripsi tidak dipublikasikan.

Guyton \& Hall. (2008). Buku Ajar Fisiologi Kedokteran Edisi 11. Jakarta: EGC.

Hambly, P. R. \& Sainsbury, M. C. (2007). Manajemen Perioperatif Penatalaksanaan Pasien Bedah di Bangsal. Jakarta: EGC.

Harsono. (2010). Faktor-faktor yang mempengaruhi intensitas nyeri pasca bedah abdomen dalam konteks asuhan keperawatan di Rumah Sakit Umum Daerah Ade Mohammad Djoen Sintang. Diperoleh pada tanggal 04 Januari 2011 dari

http://jurnal.dikti.go.id/jurnal/detil/id/0:23 370/q/pengarang: Harsono/ offset/0/limit/15.

Hidayat, A. A. A. (2006). Pengantar Kebutuhan Dasar Manusia Aplikasi Konsep dan Proses Keperawatan. Jakarta: Salemba Medika.

Hidayat, A. A. A. (2007). Riset Keperawatan \& Teknik Penulisan Ilmiah. Jakarta: Salemba Medika.

Hidayat, A. A. A. (2008). Metode Penelitian Keperawatan \& Teknik Analisis Data. Jakarta: Salemba Medika.

Isbagio, H. (2006). Perhatian Dunia Terhadap Muskuloskeletal. Diperoleh pada tanggal 01 Agustus 2010 dari http://www.majalah-farmacia.com/ rubrik/one_news.asp?IDNews=28.

Jayanthi, N. (2010). Teknik Relaksasi Napas Dalam. Diperoleh pada tanggal 25 September $2010 \quad$ dari http://www.rentalhikari.wordpress.com/re 
ISSN: 2621-6612

Email: d3perinfokesunivet@gmail.com

Halaman: 16-21

search-penelitian/2010/02/23/teknikrelaksasi-napas-dalam/.

Lehndorff, P.G. (2005). 60 second Meredakan Rasa Sakit. Jakarta: Buana Ilmu Populer

Notoatmodjo, S. (2005). Metodologi Penelitian Kesehatan. Jakarta: Rineka Cipta.

Nursalam. (2008). Konsep Penerapan Metodologi Penelitian Ilmu Keperawan. Jakarta: Salemba Medika.

PERSI. (2001). Indonesia Akan Canangkan Dekade Tulang dan Sendi. Diperoleh pada tanggal 31 july 2010 dari http://www.pdpersi.

co.id/?show=detailnews $\&$ kode $=579 \&$ tbl $=$ cakrawala.

Potter, P. A. \& Perry, A. G. (2006). Buku Ajar Fumdamental Keperawatan Konsep, Proses, dan Praktik Edisi 4. Jakarta: EGC.

Price, S. A. \& Wilson, L. M. (2006). Patofisiologi Konsep Klinis ProsesProses Penyakit Edisi 6. Jakarta: EGC.

Priharjo, R. (2003). Perawatan Nyeri Pemenuhan Aktivitas Istirahat Pasien. Jakarta: EGC.

Priyani, N. P. A. (2009). Abstrak Pengaruh Pemberian Teknik Relaksasi Napas Dalam Terhadap Penurunan Nyeri Dismenore Pada Remaja Putri Di Panti Asuhan Yatim Putri Islam Yogyakarta. Diperoleh pada tanggal 19 Agustus 2010 dari

http://skripsistikes.wordpress.com/2009/0 5/03/ikpiii99/.

Putra, R.A.D. (2010). Efektifitas Kompres Hangat Pada Area Lumbal Terhadap Penurunan Nyeri Pasca Bedah Fraktur Ekstremitas Bawah. Sripsi tidak dipublikasikan.

Ilmi, Z. (2010). Efektifitas Teknik Relaksasi Napas Dalam dan Zikir terhadap
Perubahan Skala Nyeri Pada Pasien Post Laparatomi. Skripsi tidak dipublikasikan.

Reeves, C. J. Roux, \& G. Lockhart, R. (2001). Keperawatan Medical Bedah Buku Satu. Jakarta : Salemba Medika.

Saryono \& Kamaluddin, R. (2008). Pemenuhan Kebutuhan Mobilitas Fisik pada Pasien di Ruang Bedah. Jakarta: Rekatama.

Shirley, A. (2009). Deep-breathing-and-painmanagement. Diperoleh pada tanggal 25 September $2010 \quad$ dari http://www.ideafit.com/fitnesslibrary/deep-breathing-and-painmanagement.

Sjamsuhidajat, R \& Jong, W.D. (2005). Buku Ajar Ilmu Bedah. Jakarta: EGC.

Smeltzer, S. C. \& Bare, B. G. (2002a). Buku Ajar Keperawatan Medikal Bedah Brunner \& Suddarth Edisi 8. Jakarta : EGC.

Smeltzer, S. C. \& Bare, B. G. (2002b). Buku Ajar Keperawatan Medikal Bedah Brunner \& Suddarth Edisi 8. Jakarta : EGC.

Sugiyono. (2010). Statistika untuk Penelitian. Bandung: Alfabeta.

Victorian Quality Council. (2007). Pain Rating Scale. Diperoleh pada tanggal 30 September $2010 \quad$ dari http://www.health.vic.gov.au/ qualitycouncil/activities/acute/index.htm 